\title{
Thyroid hormone and the stunned myocardium
}

\author{
Dimitri Novitzky and David K C Cooper ${ }^{1}$ \\ Formerly Professor of Cardiothoracic Surgery, University of South Florida, Tampa, Florida, USA \\ ${ }^{1}$ Thomas E. Starzl Transplantation Institute, University of Pittsburgh Medical Center, \\ Starzl Biomedical Science Tower, W1543, 200 Lothrop Street, Pittsburgh, Pennsylvania 15261, USA
}

Correspondence should be addressed to D K C Cooper Email cooperdk@upmc.edu

\begin{abstract}
Acute critically ill patients experience a rapid decline in plasma free thyroid hormone levels (free triiodothyronine $\left(\mathrm{FT}_{3}\right)$ and free levothyroxine $\left(\mathrm{FT}_{4}\right)$ ), with a marked elevation of reverse $\mathrm{T}_{3}$, recognized as the euthyroid sick syndrome (ESS) or low- $T_{3}$ syndrome. The ESS is also often associated with depressed myocardial function, sometimes referred to as the 'stunned myocardium'. Its clinical effects may vary from minimal hemodynamic impairment to cardiogenic shock. Medical management may range from aspirin alone to placement of a left ventricular assist device. With adequate supportive therapy, recovery usually occurs within days or weeks. The effect of $\mathrm{T}_{3} / \mathrm{T}_{4}$ therapy has been studied in three conditions in which the ESS and myocardial functional depression have been documented - i) transient regional myocardial ischemia and reperfusion, ii) transient global myocardial ischemia in patients undergoing cardiac surgery on cardiopulmonary bypass, and iii) transient inadequate global myocardial perfusion in brain-dead potential organ donors. Under all three conditions, myocardial ischemia leads to rapid loss of high-energy phosphates, accumulation of myocardial tissue lactate, and probably loss of homeostasis of cytosolic calcium, which may further increase cell injury. There is an inability to generate ATP through the Krebs cycle, which reduces the high-energy phosphate pool essential for all cell ATPases. Under all three conditions, following administration of $\mathrm{T}_{3} / \mathrm{T}_{4}$, the myocardial dysfunction was rapidly reversed. We, therefore, cautiously advocate the use of thyroid hormonal therapy to any patient with the ESS and/or a stunned myocardium.
\end{abstract}

Journal of Endocrinology (2014) 223, R1-R8

\section{Introduction: thyroid hormone and the euthyroid sick syndrome}

Thyroid hormone production, function, and interaction with other endocrine systems are well understood (Flood et al. 2013, Duarte-Guterman et al. 2014). Control of the thyroid gland is regulated by hypothalamic and paraventricular nuclei, which release thyroid-releasing hormone directly into the hypothalamic hypophyseal portal venous system, which drains into the anterior pituitary gland, stimulating the release of thyroid-stimulating hormone (TSH), which controls thyroid hormone storage and release (Fliers et al. 2006). Most (90\%) of the secreted thyroid hormone is tetraiodothyronine $\left(\mathrm{T}_{4}\right.$, levothyroxine) and the remaining $10 \%$ is triiodothyronine $\left(\mathrm{T}_{3}\right)$. These hormones are rapidly bound to proteins, and the amount that remains free in the plasma is small; approximately $5 \%$ of $\mathrm{T}_{3}\left(\mathrm{FT}_{3}\right)$ and $10 \%$ of $\mathrm{T}_{4}\left(\mathrm{FT}_{4}\right)$ is free (Fliers et al. 2006).

$\mathrm{T}_{3}$ is the active thyroid hormone, and all $\mathrm{T}_{4}$ secreted by the thyroid gland is converted into $T_{3}$ or reverse $T_{3}\left(r T_{3}\right)$. Intracellular $\mathrm{T}_{3}$ has approximately 20 times more potency 
than $\mathrm{T}_{4}$. Thyroid hormones are essential for proper aerobic mitochondrial function, generation of high-energy phosphates, activation of adenine nucleotide transferase, and prevention of tissue lactic acidosis (Novitzky et al. 1988a). $\mathrm{T}_{3} / \mathrm{T}_{4}$ play an important role in intracellular homeostasis of ionized calcium (Straub 2014), thereby avoiding calcium-induced injury (Oshiro et al. 2001), mobilizing cytosolic calcium into the sarcoplasmic reticulum, and participating in calcium uptake/calcium release during depolarization/repolarization of myocytes (Zarain-Herzberg \& Alvarez-Fernandez 2002). They also play a role in the up-regulation of $\beta$ adrenergic receptors and protein synthesis. Thyroid hormones affect excitation/ contractility coupling and have inotropic properties (Ririe et al. 1995), which are dose-dependent (Snow et al. 1992), and are strong vasodilators of systemic arteries, including coronary arteries (Klein 2001).

Acute critically ill patients (medical or surgical), who prior to developing the illness/condition were euthyroid and had normal plasma free thyroid hormone levels, experience a rapid decline in $\mathrm{FT}_{3}$ and $\mathrm{FT}_{4}$, with a marked elevation of plasma levels of $\mathrm{rT}_{3}$ (Warner \& Beckett 2010). $\mathrm{FT}_{3}$ plasma levels may fall by $70-90 \%$. The severity of reduction in $\mathrm{FT}_{3} / \mathrm{FT}_{4}$ has been shown to correlate with patient mortality. TSH levels usually remain within the normal range, though in very sick patients they may be reduced, but not as markedly as $\mathrm{FT}_{3}$ and $\mathrm{FT}_{4}$. These acute changes are recognized as the euthyroid sick syndrome (ESS) or low- $\mathrm{T}_{3}$ syndrome.

Following exposure to an acute pathogenic event (medical, surgical, traumatic), ESS has been observed in the majority of patients admitted to a medical or surgical intensive care unit in practically every acute or chronic stress condition (Table 1). Its cause may be multifactorial. ESS is frequently associated with the presence of high levels of plasma and/or tissue catecholamines (endogenous or exogenous) (Mebis et al. 2009), but may also be associated with an inflammatory response. Among multiple markers, tumor necrosis factor-alpha (TNF- $\alpha$ ) may participate in the mediation of the ESS. For example, the infusion of TNF- $\alpha$ in humans results in a decrease in serum $\mathrm{T}_{3}, \mathrm{~T}_{4}$, and TSH levels, and a rise in $\mathrm{rT}_{3}$ (van der Poll et al. 1990). The infusion of interleukin-1 (IL1) (Hermus et al. 1992), IL6 (Bartalena et al. 1994, Stouthard et al. 1994), or interferon-alpha (IFN- $\alpha$ ) (Corssmit et al. 1995) produces a similar effect. As both TNF- $\alpha$ and IL $1 \alpha$ can induce the release of IL6, this indicates that IL6 may be the mediator of cytokine-induced changes in thyroid hormones.

ESS is often associated with depressed myocardial function. Inadequate organ perfusion, in turn, precipitates
Table 1 Conditions in which the euthyroid sick syndrome (ESS) has been described ${ }^{a}$

Acute myocardial infarction, post-cardiac arrest, and low cardiac output related to myocardial dysfunction

Autoimmune diseases

Brain injury and brain death, including brain-dead organ donors

Cardiac surgery on cardiopulmonary bypass

Chronic infection (e.g., cystic fibrosis, tuberculosis, fungal)

Critically-ill ICU patients (from any cause)

Diabetes (uncontrolled, ketoacidosis)

End-stage organ failure, including patients awaiting organ transplantation

Fasting (severe prolonged)

Malignant disease

Sepsis

Shock (hemorrhagic, septic)

Steroid therapy (prolonged)

Trauma

${ }^{\text {a } F r o m ~ N o v i t z k y ~ D ~ \& ~ C o o p e r ~ D K C ~} 2013$ Thyroid hormone therapy to the recipient of a heart from a brain-dead donor. In The Brain-Dead Organ Donor: Pathophysiology and Management, p 322. Eds D Novitzky \& DKC Cooper. New York: Springer (with permission).

an inflammatory response, with release of oxygen free radicals, which may further compromise myocardial contractility. Multiorgan failure is not unusual (Gou et al. 2006). The myocardial dysfunction is usually transient and is sometimes referred to as the 'stunned myocardium'.

\section{The stunned myocardium and the ESS}

The term 'stunned myocardium' is used in conditions in which the myocardium is depressed following a regional or global ischemic event (Bolling et al. 1994, Kloner \& Jennings 2001, Luo et al. 2010, Heusch 2013). The affected myocardial territory may range from a small volume of myocardial tissue to the entire heart. Its clinical effects may, therefore, vary from minimal hemodynamic impairment to cardiogenic shock. Transient ischemic events may not be severe enough to induce myocyte necrosis, but the myocardium loses its ability to perform work normally. The level of the functional depression is related to the extent of the myocardial ischemia. Its natural course is for recovery to occur within days or possibly weeks. Medical management may range from the administration of aspirin alone to placement of a left ventricular assist device.

\section{Thyroid hormones in the treatment of the ESS}

Plasma thyroid hormone values recover once the underlying pathological condition, e.g., pneumonia, myocardial ischemia related to open heart surgery, has been

Published by Bioscientifica Ltd 
reversed. The current consensus, therefore, is that patients exhibiting the ESS should not be subjected to thyroid replacement therapy as it is not believed that the administration of thyroid hormone changes the outcome of the primary disease (Bello et al. 2010, Pappa et al. 2011).

In our experience, however, the administration of $\mathrm{T}_{3} / \mathrm{T}_{4}$ has been rewarding in conditions in which myocardial 'stunning' plays a role. These include any condition in which a period of regional or global myocardial ischemia (inadequate blood perfusion) has occurred followed by revascularization and/or reperfusion. In particular, the effect of $T_{3} / T_{4}$ therapy has been studied under three conditions in which the ESS and myocardial functional depression have been documented - i) transient regional myocardial ischemia and reperfusion (Heusch 2013), ii) transient global myocardial ischemia in patients undergoing cardiac surgery on cardiopulmonary bypass (CPB) (Siribaddana 2012), and iii) transient inadequate global myocardial perfusion in brain-dead potential organ donors (Novitzky et al. 1984). Under all three conditions, following administration of $\mathrm{T}_{3} / \mathrm{T}_{4}$, the myocardial dysfunction was rapidly reversed.

We, therefore, suggest that $T_{3} / T_{4}$ therapy may be beneficial not only for these conditions but for any condition that has resulted in a stunned myocardium.

\section{Studies on $\mathrm{T}_{3}$ therapy in transient regional myocardial ischemia and reperfusion in dogs}

Two groups of dogs were subjected to a 15-min period of regional myocardial ischemia by snaring the left anterior descending coronary artery distal to its first diagonal branch (Novitzky et al. 1991, Yokoyama et al. 1992). After the release of the snare, the dogs were given either placebo or $\mathrm{T}_{3}(0.2 \mu \mathrm{g} / \mathrm{kg})$ at $30-\mathrm{min}$ intervals.

Plasma $\mathrm{FT}_{3}$ levels fell significantly during the ischemic period in both groups and continued to fall after reperfusion in the untreated group. In both groups, cardiac function deteriorated significantly during the period of ischemia, but rapidly returned to control levels after reperfusion. After $90 \mathrm{~min}$ of reperfusion, however, deterioration of left ventricular function was observed in untreated dogs and was significantly worse than in the $T_{3}$-treated dogs, in which hemodynamic function was maintained and, in fact, improved to levels superior to those of controls.

This study indicated that regional myocardial ischemia alone reduces $\mathrm{FT}_{3}$ levels, and that $\mathrm{T}_{3}$ therapy might be worthy of a trial in patients with a stunned myocardium in whom reperfusion of the myocardium takes place after variable periods of ischemia.

\section{Studies on $\mathrm{T}_{3}$ therapy following transient global myocardial ischemia and CPB}

A significant reduction in plasma $\mathrm{FT}_{3}$ has been documented in patients undergoing open heart procedures on $\mathrm{CPB}$ (Bremner et al. 1978, Robuschi et al. 1986, Novitzky et al. 1989a, Novitzky \& Cooper 1990). We proposed the hypothesis that it was this reduction in circulating $\mathrm{FT}_{3}$ that was in part responsible for a deterioration of myocardial function in such patients.

\section{Studies in pigs and baboons}

Twenty-two pigs underwent 2 or $3 \mathrm{~h}$ of myocardial ischemia (cross-clamping of the ascending aorta) during $\mathrm{CPB}$ at $26^{\circ} \mathrm{C}$ (Novitzky et al. 1988b). The myocardium was protected by a cardioplegic solution and by the local application of cold saline solution. After the pig was rewarmed to $37^{\circ} \mathrm{C}, \mathrm{CPB}$ was discontinued, and measurements of hemodynamic function were made 10 and $70 \mathrm{~min}$ later. Half of the pigs received $6 \mu \mathrm{g}$ of $\mathrm{T}_{3}$ i.v. immediately after the removal of the aortic cross-clamp, the remainder receiving no $\mathrm{T}_{3}$.

After $2 \mathrm{~h}$ of ischemia, untreated pigs showed significantly reduced myocardial function $10 \mathrm{~min}$ after discontinuation of CPB. By $70 \mathrm{~min}$, two of five untreated pigs had died of low cardiac output, but all five $\mathrm{T}_{3}$-treated pigs survived. After $3 \mathrm{~h}$ of ischemia, both groups showed some reduced function at $10 \mathrm{~min}$, although the reduction was more marked in untreated animals. By $70 \mathrm{~min}$, four of six untreated pigs had died of myocardial failure and all $\mathrm{T}_{3}$-treated pigs remained alive. Surviving pigs in both groups still demonstrated some reduced function compared with values obtained before $\mathrm{CPB}$.

To clarify the effect of $\mathrm{T}_{3}$ on myocardial high-energy phosphate stores and lactate, a series of experiments were carried out in baboons undergoing $3 \mathrm{~h}$ of myocardial ischemia while supported by CPB (Novitzky et al. 1988c). At the end of the ischemic period, six received $6 \mu \mathrm{g}$ of $\mathrm{T}_{3}$, and seven received no $T_{3}$. Seventy minutes after $\mathrm{CPB}$, the myocardial ATP level was significantly higher in the treated animals. In untreated animals, a steady increase in myocardial lactate occurred, and $70 \mathrm{~min}$ after CPB was discontinued, there was a significant difference in lactate levels between the two groups.

On the basis of these results, it was postulated that a combination of global ischemia and depletion of $\mathrm{FT}_{3}$ resulted in reduced mitochondrial function, inhibition of the tricarboxylic acid cycle, inability to utilize oxygen aerobically with resulting increased anaerobic metabolism,

Published by Bioscientifica Ltd. 
and depletion of myocardial phosphates. $\mathrm{T}_{3}$ replacement therapy was presumed to improve mitochondrial function and increase aerobic metabolism, which led to a measured increase in myocardial phosphates.

\section{Studies in patients undergoing open heart surgery on CPB}

Initially, we administered $\mathrm{T}_{3}$ (4-10 $\mu$ g i.v.) to ten patients, either when difficulty was being experienced in weaning from $\mathrm{CPB}$ support $(n=5)$ or when myocardial function remained extremely poor, despite inotropic and intra-aortic balloon pump support ( $n=5$ ) (Novitzky et al. 1989b).

Within $1 \mathrm{~h}$ of $\mathrm{T}_{3}$ administration, the mean plasma free $\mathrm{T}_{3}$ level had risen from 1.03 to $3.56 \mu \mathrm{g} / \mathrm{ml}$, and CPB was able to be discontinued in all cases. At $1 \mathrm{~h}$, the mean arterial pressure had risen from 42 to $78 \mathrm{mmHg}$, and heart rate from 90 to 104 beats $/ \mathrm{min}$. The left atrial pressure had fallen from 30 to $14 \mathrm{mmHg}$, and the central venous pressure from 20 to $11 \mathrm{~cm} \mathrm{H}_{2} \mathrm{O}$. All changes were statistically significant. Inotropic support had been significantly reduced or discontinued. Within $3 \mathrm{~h}$, intra-aortic balloon pump support $(n=2)$ was no longer essential.

To the best of our knowledge, $T_{3}$ had not been administered previously as an inotropic agent to patients who had undergone cardiac surgery. Although this small trial was not randomized, the results indicated that $T_{3}$ could play an important role in the rescue of failing hearts following a period of myocardial ischemia in patients who had undergone open heart surgery.

Subsequently, in two small randomized trials in patients undergoing myocardial revascularization on $\mathrm{CPB}$, postoperative $\mathrm{T}_{3}$ therapy was associated with a reduced need for inotropic support and diuretic therapy (in the first study) and improved cardiac output (in the second study) (Novitzky et al. 1989b). A later study added support to these observations (Novitzky et al. 1996).

Others subsequently continued to study the effects of CPB on thyroid hormones and the effect of thyroid hormones on myocardial function (Dyke et al. 1991, Clark 1993, Lowenstein 1993).

\section{Studies on $\mathrm{T}_{3}$ therapy after brain death}

Myocardial stunning has been observed during and following the induction of brain death. This injury occurs at a time of massive release of endogenous catecholamines (Novitzky et al. 1984, Shivalkar et al. 1993). Electrocardiographic changes correlate well with acute ongoing myocardial ischemia and on occasions mimic an acute myocardial infarction. The catecholamine storm is short-lived, but myocardial injury can be observed under the microscope, and can be prevented by pretreatment with $\beta$ blockade or calcium antagonists (Novitzky et al. 1987a).

The surge in catecholamines is associated with rapid declines in plasma levels of $\mathrm{T}_{3}, \mathrm{~T}_{4}$, cortisol, insulin, and antidiuretic hormone (Novitzky et al. 1984, 1987a, Cooper et al. 1989). However, TSH remains within the normal range.

\section{Studies in brain-dead pigs and baboons}

The most relevant experiments demonstrated that brain-dead animals were unable to aerobically metabolize radiolabeled metabolites $\left({ }^{14} \mathrm{C}\right.$-U-glucose, ${ }^{14} \mathrm{C}$-1-palmitate, and ${ }^{14} \mathrm{C}$-1-pyruvate) administered intravenously (Novitzky et al. 1988b). There was a major change in metabolic oxidative processes. The rate of glucose, pyruvate, and palmitate utilization was markedly reduced, and there was an accumulation of lactate and free fatty acids in the plasma, indicating a change from aerobic to anaerobic metabolism. These metabolic changes were associated with a significant decline in myocardial function. The administration of $\mathrm{T}_{3}$ to the brain-dead animals resulted in a dramatic increase in the rate of metabolite utilization, and a reduction in the plasma concentrations of plasma lactate and free fatty acids, indicating reversal from anaerobic to aerobic tissue metabolism.

The inability of the brain-dead animal to metabolize cellular fuels aerobically indicates that the mitochondria are no longer functioning and are unable to generate highenergy phosphates; pyruvate does not enter into the mitochondria, but accumulates as lactate (Novitzky et al. $1988 b$, Stacpoole 1997). As time post-brain-death progresses, the inhibition of the Krebs cycle becomes greater, and mitochondrial failure leads to i) depletion of highenergy phosphates, ii) tissue lactic acidosis (Sztark et al. 2000), iii) loss of cellular homeostasis, iv) inability to maintain ionic ATPase function v) inability to maintain ion compartmentalization, and vi) deactivation of sodium/potassium cellular pumps. Increments of cytosolic calcium uptake no longer occur, and calcium is released from the sarcoplasmic reticulum into the cytosol, eventually resulting in cell death.

These results indicated that $\mathrm{T}_{3}$ should be administered to all brain-dead potential organ donors to correct and maintain a more physiological metabolic status and thus improve organ function.

\section{Studies in human brain-dead potential organ donors}

Following brain death, recovery of myocardial perfusion results in a degree of recovery, and the heart may continue

Published by Bioscientifica Ltd 
beating well, while it remains in the vasodilated donor (where peripheral vascular resistance is low). The further period of ischemia while the donor heart is transported and transplanted may lead to further stunning and poor prolonged myocardial depression.

Hormonal therapy that included $\mathrm{T}_{3}$ was first administered to a series of brain-dead potential organ donors at Groote Schuur Hospital at the University of Cape Town in 1984 (Novitzky et al. 1986, 1987b, Cooper et al. 1989). The initial regimen involved the hourly administration of $\mathrm{T}_{3}(2 \mu \mathrm{g})$, cortisol (100 mg), and insulin (20 units).

Twenty-six conventionally treated donors (with no hormonal replacement therapy) showed abnormal electrocardiograms (resembling myocardial ischemia), progressive hemodynamic deterioration requiring significantly increased inotropic support to maintain hemodynamic stability, and progressive lactic acidosis requiring frequent bicarbonate administration to maintain a normal acid-base balance (Novitzky et al. 1987b). Of this group, five (19\%) of the donors were considered unsuitable as cardiac donors due to progressive cardiovascular deterioration or sudden ventricular fibrillation. Hormonal replacement therapy was administered to 21 donors, resulting in normalization of the electrocardiographic abnormalities, significant improvement in hemodynamic status, reduced inotropic support, and reduced requirement for bicarbonate. In these donors, all organs were acceptable for transplantation, which was followed by excellent organ function in the recipients.

Thyroid hormone therapy of the brain-dead potential organ donors remained controversial for many years and is still not universally administered (Macdonald et al. 2012, Rech et al. 2013). We have, therefore, recently reviewed data provided by the United Network for Organ Sharing (UNOS) on hormonal resuscitation therapy in the management of 63593 brain-dead potential organ donors in the USA in the 10-year period 2000-2009 (Novitzky et al. 2014). There was a clear benefit in terms of the number of organs that could be procured (and transplanted) from donors that received $\mathrm{T}_{3} / \mathrm{T}_{4}$ when compared with those that did not, representing an increase in organs procured of $12.8 \%(P<0.0001)$.

In a cohort of 40124 donors in which details of all hormonal therapy were available, there was a clearly increased procurement/transplantation rate for the heart, lung, kidney, pancreas, and intestine when $\mathrm{T}_{3} / \mathrm{T}_{4}$ had been administered. There was no overall benefit of $T_{3} / T_{4}$ on liver procurement, although one subgroup showed a significantly higher procurement rate when $T_{3} / T_{4}$ was administered, and in the other subgroups there was no detrimental effect.

\section{Thyroid hormone therapy: potential mechanisms}

All of the conditions described above demonstrate variable degrees of myocardial stunning. The myocardial ischemia leads to rapid loss of high-energy phosphates, accumulation of myocardial tissue lactate, and probably loss of homeostasis of cytosolic calcium, which may further increase cell injury. There may also be mitochondrial injury, which varies in degree. There is an inability to generate ATP through the Krebs cycle, which reduces the high-energy phosphate pool essential for all cell ATPases.

Total nucleotides may remain reduced for several days, as there is a relatively slow process of de novo synthesis. The mechanism of action of the thyroid hormones has been discussed previously (Song et al. 2007, Shapiro \& Baron 2013) and will not be considered in detail here. In summary, these hormones appear essential for reactivation of mitochondrial energy metabolism (in the Krebs cycle), and this contributes to hemodynamic stability. $\mathrm{T}_{3}$ may facilitate recovery of the stunned myocardium by increasing ATP, and by activating the adenyl nucleotide transferase, enhancing the transfer of ATP from the mitochondria into the cytosol. Exogenous $\mathrm{T}_{3}$ may have an effect on the cytosolic ATPases, affecting ATP-dependent ionic pumps, such as the calcium pumps, and calcium is rapidly mobilized in the sarcoplasmic reticulum.

For example, brain-dead organ donors suffer from various degrees of deprivation of high-energy phosphates and, as time passes, there is a progressive accumulation of tissue and plasma lactate, which, despite bicarbonate replacement, leads to progressive acidosis. These donors progressively become refractory to exogenous catecholamines and are eventually lost from the donor pool due to hemodynamic instability. The pathophysiology of brain death and the mechanisms by which hormonal therapy may improve donor organ function have recently been comprehensively reviewed (Novitzky \& Cooper 2013).

The mechanisms related to the beneficial effects of thyroid hormone on the stunned myocardium have been investigated by several groups, but particularly by Pantos \& Mourouzis (2014). Once thought to be detrimental to the ischemic myocardium, thyroid hormones are now recognized to have anti-ischemic and inotropic actions. Indeed, they can protect against the detrimental effects of inotropic agents that exacerbate post-ischemic myocardial dysfunction (Pantos et al. 2003a). However, in addition to their action on metabolism and calcium handling, there is increasing evidence of their effect on stress-induced intracellular signaling, in part related to inhibition of apoptosis,

Published by Bioscientifica Ltd. 
mediated through thyroid hormone receptor $\alpha 1$ (Pantos et al. 2009, 2011, Pantos \& Mourouzis 2014). This may explain why $\mathrm{T}_{3}$ is more effective than $\mathrm{T}_{4}$ (Pantos et al. 2009, 2011, Pantos \& Mourouzis 2014). Thyroid hormone enhances the activation of Akt signaling, which is essential for mitochondrial function (Mourouzis et al. 2012, Adamopoulos et al. 2013). Furthermore, thyroid hormone increases basal expression and phosphorylation of heat shock protein-27, conferring protection of the myocardium against ischemia-reperfusion injury (Pantos et al. 2003b).

We, therefore, cautiously advocate the use of thyroid hormonal therapy to any patient with the ESS and/or a stunned myocardium, as also recommended by others (de Groot 2006). In the field of organ transplantation, $\mathrm{T}_{3} / \mathrm{T}_{4}$ therapy is advocated for the donor and, because the patient undergoing heart transplantation has been supported by a period of CPB (resulting in a low $\mathrm{FT}_{3}$ ), we also recommend $\mathrm{T}_{3}$ therapy for the recipient (Novitzky et al. 1988d, 1990). By correcting the metabolic derangements that take place in the donor, the heart will be excised with close to normal levels of energy stores that can be utilized during the period of myocardial ischemia, while the heart is transported to the recipient center and transplanted into the recipient. $T_{3}$ replacement therapy administered to the recipient, before the removal of the aortic cross-clamp, will lead to rapid restoration of energy stores that may have decreased during $\mathrm{CPB}$, with associated improvement in myocardial function.

In summary, patients who exhibit the ESS (whatever the underlying cause) may experience acute myocardial depression, which may require some type of cardiac support. This may involve inotropic agents, placement of an intra-aortic balloon pump, or even mechanical support of the heart. Thyroid replacement therapy may rapidly reverse this state of myocardial dysfunction, allowing all forms of myocardial support to be discontinued or significantly reduced.

\section{Declaration of interest}

The authors declare that there is no conflict of interest that could be perceived as prejudicing the impartiality of the review.

\section{Funding}

This research did not receive any specific grant from any funding agency in the public, commercial, or not-for-profit sector.

\section{Acknowledgements}

The authors acknowledge with gratitude the data provided by UNOS.

\section{References}

Adamopoulos S, Gouziouta A, Mantzouratou P, Laoutaris ID, Dritsas A, Cokkinos DV, Mourouzis I, Sfyrakis P, Iervasi G \& Pantos C 2013 Thyroid hormone signalling is altered in response to physical training in patients with end-stage heart failure and mechanical assist devices: potential physiological consequences? Interactive Cardiovascular and Thoracic Surgery 17 664-668. (doi:10.1093/icvts/ivt294)

Bartalena L, Brogioni S, Grasso L, Velluzzi F \& Martino E 1994 Relationship of the increased serum interleukin- 6 concentration to changes of thyroid function in nonthyroidal illness. Journal of Endocrinological Investigation 17 269-274. (doi:10.1007/BF03348974)

Bello G, Ceaichisciuc I, Silva S \& Antonelli M 2010 The role of thyroid dysfunction in the critically ill: a review of the literature. Minerva Anestesiologica 76 919-928.

Bolling SF, Olszanski DA, Childs KF, Gallagher KP \& Ning XH 1994 Stunning, preconditioning, and functional recovery after global myocardial ischemia. Annals of Thoracic Surgery 58 822-827. (doi:10.1016/0003-4975(94)90759-5)

Bremner WF, Taylor KM, Baird S, Thomson JE, Thomson JA, Ratcliffe JG, Lawrie TD \& Bain WH 1978 Hypothalamo-pituitary-thyroid axis function during cardiopulmonary bypass. Journal of Thoracic and Cardiovascular Surgery 75 392-399.

Clark RE 1993 Cardiopulmonary bypass and thyroid hormone metabolism. Annals of Thoracic Surgery 56 S35-S41 discussion S41-42. (doi:10.1016/ 0003-4975(93)90552-S)

Cooper DK, Novitzky D \& Wicomb WN 1989 The pathophysiological effects of brain death on potential donor organs, with particular reference to the heart. Annals of the Royal College of Surgeons of England 71 261-266.

Corssmit EP, Heyligenberg R, Endert E, Sauerwein HP \& Romijn JA 1995 Acute effects of interferon- $\alpha$ administration on thyroid hormone metabolism in healthy men. Journal of Clinical Endocrinology and Metabolism 80 3140-3144. (doi:10.1210/jcem.80.11.7593416)

Duarte-Guterman P, Navarro-Martin L \& Trudeau VL 2014 Mechanisms of crosstalk between endocrine systems: regulation of sex steroid hormone synthesis and action by thyroid hormones. General and Comparative Endocrinology 203 69-85. (doi:10.1016/j.ygcen. 2014.03.015)

Dyke CM, Yeh T Jr, Lehman JD, Abd-Elfattah A, Ding M, Wechsler AS \& Salter DR 1991 Triiodothyronine-enhanced left ventricular function after ischemic injury. Annals of Thoracic Surgery 52 14-19. (doi:10.1016/ 0003-4975(91)91410-W)

Fliers E, Alkemade A, Wiersinga WM \& Swaab DF 2006 Hypothalamic thyroid hormone feedback in health and disease. Progress in Brain Research 153 189-207. (doi:10.1016/S0079-6123(06)53011-0)

Flood DE, Fernandino JI \& Langlois VS 2013 Thyroid hormones in male reproductive development: evidence for direct crosstalk between the androgen and thyroid hormone axes. General and Comparative Endocrinology 192 2-14. (doi:10.1016/j.ygcen.2013.02.038)

Gou DY, Su W, Shao YC \& Lu YL 2006 Euthyroid sick syndrome in trauma patients with severe inflammatory response syndrome. Chinese Journal of Traumatology 9 115-117.

de Groot LJ 2006 Non-thyroidal illness syndrome is a manifestation of hypothalamic-pituitary dysfunction, and in view of current evidence, should be treated with appropriate replacement therapies. Critical Care Clinics 22 57-86. (doi:10.1016/j.ccc.2005.10.001)

Hermus RM, Sweep CG, van der Meer MJ, Ross HA, Smals AG, Benraad TJ \& Kloppenborg PW 1992 Continuous infusion of interleukin-1 $\beta$ induces a nonthyroidal illness syndrome in the rat. Endocrinology 131 2139-2146. (doi:10.1210/endo.131.5.1425414)

Heusch G 2013 The regional myocardial flow-function relationship: a framework for an understanding of acute ischemia, hibernation, stunning and coronary microembolization. 1980. Circulation Research 112 1535-1537. (doi:10.1161/CIRCRESAHA.113.301446) http://joe.endocrinology-journals.org DOI: 10.1530/JOE-14-0389
(C) 2014 Society for Endocrinology Printed in Great Britain 
Klein I 2001 Clinical, metabolic, and organ-specific indices of thyroid function. Endocrinology and Metabolism Clinics of North America 30 415-427. (doi:10.1016/S0889-8529(05)70193-6)

Kloner RA \& Jennings RB 2001 Consequences of brief ischemia: stunning, preconditioning, and their clinical implications: part 1. Circulation 104 2981-2989. (doi:10.1161/hc4801.100038)

Lowenstein E 1993 Implications of triiodothyronine administration before cardiac and noncardiac operations. Annals of Thoracic Surgery 56 S43-S46 discussion S46-47. (doi:10.1016/0003-4975(93)90553-T)

Luo Y, Cha DG, Liu YL \& Zhou SF 2010 Coronary microcirculation changes during myocardial stunning in dogs. Cardiology 117 68-74 (doi:10.1159/000319616)

Macdonald PS, Aneman A, Bhonagiri D, Jones D, O'Callaghan G, Silvester W, Watson A \& Dobb G 2012 A systematic review and meta-analysis of clinical trials of thyroid hormone administration to brain dead potential organ donors. Critical Care Medicine 40 1635-1644. (doi:10.1097/CCM.0b013e3182416ee7)

Mebis L, Paletta D, Debaveye Y, Ellger B, Langouche L, D'Hoore A, Darras VM, Visser TJ \& Van den Berghe G 2009 Expression of thyroid hormone transporters during critical illness. European Journal of Endocrinology 161 243-250. (doi:10.1530/EJE-09-0290)

Mourouzis I, Mantzouratou P, Galanopoulos G, Kostakou E, Roukounakis N, Kokkinos AD, Cokkinos DV \& Pantos C 2012 Dose-dependent effects of thyroid hormone on post-ischemic cardiac performance: potential involvement of Akt and ERK signalings. Molecular and Cellular Biochemistry 363 235-243. (doi:10.1007/s11010-011-1175-9)

Novitzky D \& Cooper DK 1990 Changes in triiodothyronine during cardiopulmonary bypass: a clinical problem? (reply to letter) Journal of Thoracic and Cardiovascular Surgery 100465.

Novitzky D \& Cooper DKC 2013 The Brain-Dead Organ Donor: Pathophysiology and Management, Eds D Novitzky \& DKC Cooper. New York: Springer.

Novitzky D, Wicomb WN, Cooper DK, Rose AG, Fraser R \& Barnard CN 1984 Electrocardiographic, hemodynamic and endocrine changes occurring during experimental brain death in the Chacma baboon. Journal of Heart Transplantation 4 63-69.

Novitzky D, Cooper DK \& Reichart B 1986 Value of triiodothyronine $\left(\mathrm{T}_{3}\right)$ therapy to brain-dead potential organ donors. Journal of Heart Transplantation 5 486-487.

Novitzky D, Cooper DK, Rose AG \& Reichart B 1987a Prevention of myocardial injury by pretreatment with verapamil hydrochloride prior to experimental brain death: efficacy in a baboon model. American Journal of Emergency Medicine 5 11-18. (doi:10.1016/07356757(87)90282-8)

Novitzky D, Cooper DK \& Reichart B 1987b Hemodynamic and metabolic responses to hormonal therapy in brain-dead potential organ donors. Transplantation 43 852-854. (doi:10.1097/00007890-19874306000016)

Novitzky D, Cooper DK, Morrell D \& Isaacs S $1988 a$ Change from aerobic to anaerobic metabolism after brain death, and reversal following triiodothyronine therapy. Transplantation 45 32-36. (doi:10.1097/ 00007890-198801000-00008)

Novitzky D, Human PA \& Cooper DK 1988b Inotropic effect of triiodothyronine following myocardial ischemia and cardiopulmonary bypass: an experimental study in pigs. Annals of Thoracic Surgery $\mathbf{4 5}$ 50-55. (doi:10.1016/S0003-4975(10)62396-X)

Novitzky D, Human PA \& Cooper DK $1988 c$ Effect of triiodothyronine $\left(\mathrm{T}_{3}\right)$ on myocardial high energy phosphates and lactate after ischemia and cardiopulmonary bypass. An experimental study in baboons. Journal of Thoracic and Cardiovascular Surgery 96 600-607.

Novitzky D, Cooper DK, Human PA, Reichart B \& Zuhdi N 1988d Triiodothyronine therapy for heart donor and recipient. Journal of Heart Transplantation 7 370-376.

Novitzky D, Cooper DK \& Swanepoel A 1989a Inotropic effect of triiodothyronine $\left(\mathrm{T}_{3}\right)$ in low cardiac output following cardioplegic arrest and cardiopulmonary bypass: an initial experience in patients DOI: 10.1530/JOE-14-0389 http://joe.endocrinology-journals.org (c) 2014 Society for Endocrinology Printed in Great Britain undergoing open heart surgery. European Journal of Cardio-Thoracic Surgery 3 140-145. (doi:10.1016/1010-7940(89)90092-4)

Novitzky D, Cooper DK, Barton CI, Greer A, Chaffin J, Grim J \& Zuhdi N $1989 b$ Triiodothyronine as an inotropic agent after open heart surgery. Journal of Thoracic and Cardiovascular Surgery 98 972-977 discussion 977-978.

Novitzky D, Cooper DK, Chaffin JS, Greer AE, DeBault LE \& Zuhdi N 1990 Improved cardiac allograft function following triiodothyronine therapy to both donor and recipient. Transplantation 49 311-316. (doi:10.1097/00007890-199002000-00017)

Novitzky D, Matthews N, Shawley D, Cooper DK \& Zuhdi N 1991 Triiodothyronine in the recovery of stunned myocardium in dogs. Annals of Thoracic Surgery 51 10-16 discussion 16-17. (doi:10.1016/ 0003-4975(91)90438-V)

Novitzky D, Fontanet H, Snyder M, Coblio N, Smith D \& Parsonnet V 1996 Impact of triiodothyronine on the survival of high-risk patients undergoing open heart surgery. Cardiology 87 509-515. (doi:10.1159/ 000177147)

Novitzky D, Mi Z, Sun Q, Collins J \& Cooper DK 2014 Thyroid hormone therapy in the management of 63,593 brain-dead organ donors: a retrospective review. Transplantation [in press]. (doi:10.1097/TP. 0000000000000187)

Oshiro Y, Shimabukuro M, Takasu N, Asahi T, Komiya I \& Yoshida H 2001 Triiodothyronine concomitantly inhibits calcium overload and postischemic myocardial stunning in diabetic rats. Life Sciences 69 1907-1918. (doi:10.1016/S0024-3205(01)01274-7)

Pantos C \& Mourouzis I 2014 The emerging role of TR $\alpha 1$ in cardiac repair: potential therapeutic implications. Oxidative Medicine and Cellular Longevity $\mathbf{2 0 1 4} 481482$.

Pantos C, Mourouzis I, Tzeis S, Moraitis P, Malliopoulou V, Cokkinos DD, Carageorgiou H, Varonos D \& Cokkinos D 2003a Dobutamine administration exacerbates postischaemic myocardial dysfunction in isolated rat hearts: an effect reversed by thyroxine pretreatment. European Journal of Pharmacology 460 155-161. (doi:10.1016/S00142999(02)02927-8)

Pantos C, Malliopoulou V, Mourouzis I, Karamanoli E, Moraitis P, Tzeis S, Paizis I, Cokkinos AD, Carageorgiou H, Varonos DD et al. 2003b Thyroxine pretreatment increases basal myocardial heat-shock protein 27 expression and accelerates translocation and phosphorylation of this protein upon ischaemia. European Journal of Pharmacology $\mathbf{4 7 8}$ 53-60. (doi:10.1016/j.ejphar.2003.08.030)

Pantos C, Mourouzis I, Saranteas T, Clave G, Ligeret H, Noack-Fraissignes P, Renard PY, Massonneau M, Perimenis P, Spanou D et al. 2009 Thyroid hormone improves postischaemic recovery of function while limiting apoptosis: a new therapeutic approach to support hemodynamics in the setting of ischaemia-reperfusion? Basic Research in Cardiology 104 69-77. (doi:10.1007/s00395-008-0758-4)

Pantos C, Mourouzis I, Saranteas T, Brozou V, Galanopoulos G, Kostopanagiotou G \& Cokkinos DV 2011 Acute $T_{3}$ treatment protects the heart against ischemia-reperfusion injury via TR $\alpha 1$ receptor. Molecular and Cellular Biochemistry 353 235-241. (doi:10.1007/s11010-011-0791-8)

Pappa TA, Vagenakis AG \& Alevizaki M 2011 The nonthyroidal illness syndrome in the non-critically ill patient. European Journal of Clinical Investigation 41 212-220. (doi:10.1111/j.1365-2362.2010.02395.x)

van der Poll T, Romijn JA, Wiersinga WM \& Sauerwein HP 1990 Tumor necrosis factor: a putative mediator of the sick euthyroid syndrome in man. Journal of Clinical Endocrinology and Metabolism 71 1567-1572. (doi:10.1210/jcem-71-6-1567)

Rech TH, Moraes RB, Crispim D, Czepielewski MA \& Leitao CB 2013 Management of the brain-dead organ donor: a systematic review and meta-analysis. Transplantation 95 966-974. (doi:10.1097/TP. Ob013e318283298e)

Ririe DG, Butterworth JF, Royster RL, MacGregor DA \& Zaloga GP 1995 Triiodothyronine increases contractility independent of $\beta$-adrenergic receptors or stimulation of cyclic-3', $5^{\prime}$-adenosine monophosphate. Anesthesiology 82 1004-1012. (doi:10.1097/00000542-199504000-00025) 
Robuschi G, Medici D, Fesani F, Barboso G, Montermini M, d'Amato L, Gardini E, Borciani E, Dall'Aglio E, Salvi M et al. 1986 Cardiopulmonary bypass: a low $\mathrm{T}_{4}$ and $\mathrm{T}_{3}$ syndrome with blunted thyrotropin (TSH) response to thyrotropin-releasing hormone (TRH). Hormone Research 23 151-158. (doi:10.1159/000180311)

Shapiro LE \& Baron T 2013 Thyroid function in health and disease, with particular reference to brain death. In The Brain-Dead Organ Donor: Pathophysiology and Management, pp 91-105. Eds D Novitzky \& DKC Cooper. New York: Springer.

Shivalkar B, Van Loon J, Wieland W, Tjandra-Maga TB, Borgers M, Plets C \& Flameng W 1993 Variable effects of explosive or gradual increase of intracranial pressure on myocardial structure and function. Circulation 87 230-239. (doi:10.1161/01.CIR.87.1.230)

Siribaddana S 2012 Cardiac dysfunction in the CABG patient. Current Opinion in Pharmacology 12 166-171. (doi:10.1016/j.coph.2012.01.010)

Snow TR, Deal MT, Connelly TS, Yokoyama Y \& Novitzky D 1992 Acute inotropic response of rabbit papillary muscle to triiodothyronine. Cardiology 80 112-117. (doi:10.1159/000174988)

Song Y, Driessens N, Costa M, De Deken X, Detours V, Corvilain B, Maenhaut C, Miot F, Van Sande J, Many MC et al. 2007 Roles of hydrogen peroxide in thyroid physiology and disease. Journal of Clinical Endocrinology and Metabolism 92 3764-3773. (doi:10.1210/ jc.2007-0660)
Stacpoole PW 1997 Lactic acidosis and other mitochondrial disorders. Metabolism 46 306-321. (doi:10.1016/S0026-0495(97)90259-6)

Stouthard JM, van der Poll T, Endert E, Bakker PJ, Veenhof CH, Sauerwein HP \& Romijn JA 1994 Effects of acute and chronic interleukin-6 administration on thyroid hormone metabolism in humans. Journal of Clinical Endocrinology and Metabolism 79 1342-1346. (doi:10.1210/ jcem.79.5.7962327)

Straub RH 2014 Interaction of the endocrine system with inflammation: a function of energy and volume regulation. Arthritis Research \& Therapy 16 203. (doi:10.1186/ar4484)

Sztark F, Thicoipe M, Lassie P, Petitjean ME \& Dabadie P 2000 Mitochondrial energy metabolism in brain-dead organ donors. Annals of Transplantation 5 41-44.

Warner MH \& Beckett GJ 2010 Mechanisms behind the non-thyroidal illness syndrome: an update. Journal of Endocrinology 205 1-13. (doi:10.1677/JOE-09-0412)

Yokoyama Y, Novitzky D, Deal MT \& Snow TR 1992 Facilitated recovery of cardiac performance by triiodothyronine following a transient ischemic insult. Cardiology 81 34-45. (doi:10.1159/000175773)

Zarain-Herzberg A \& Alvarez-Fernandez G 2002 Sarco(endo)plasmic reticulum $\mathrm{Ca}^{2+}$-ATPase-2 gene: structure and transcriptional regulation of the human gene. Scientific World Journal 2 1469-1483. (doi:10.1100/tsw.2002.228)

Received in final form 11 August 2014

Accepted 15 August 2014

Accepted Preprint published online 15 August 2014
(C) 2014 Society for Endocrinology Printed in Great Britain 